\title{
Concerns for First-Gen Political Science Graduate Students
}

\section{What do you need to know about first-gen political science graduate students?}

Many political scientists remain unversed in the relevant and diverse experiences of firstgeneration college and university students, even if they themselves were first-generation (hereafter "firstgen"). This is likely the result of many first-gen academics failing to recognize their own experiences as anything other than 'normal'. However, first-gen political science graduate students often start in a predicament that differs from students whose parents attended and graduated with an undergraduate education; without the benefit of parental mentorship and advice with regard to resources, navigating application processes, transitioning into graduate education, reading unwritten rules, and the like.

A first-generation college student is one whose parents or guardians did not complete a four-year college degree (NASPA 2017). This is a near-universal definition though the definition may be contingent upon program, department, school, university, or country. First-gen status is generally both a positionality and a topic many universities and colleges are interested in documenting for census-type reasons and for undergraduate programming. Moreover, because the significance of first-gen status will hold greater importance in graduate programs, we must also recognize concerns for first-gen political science graduate students.

While many of us have far greater clarity about first-gen identities, the first-gen label is not subject to aggressions that may often apply to race, gender, sexuality, and so on. Still, first-gen status is often part of larger intersectional identities, meaning that many first-gen students may also hold multiple identities, of which first-gen is one of many. This means that first-gen experiences among political science graduate students are not identical. The primary issues that first-gen students face are often around cultural capital (social assets they may lack in college), imposter syndrome (self-doubts they may have in college), and survivor's guilt (experiencing opportunities not available to others back home). Further interconnected challenges include an absence of belonging, unaffordability of tuition and living expenses, and academic struggles (Azmitia et al. 2018, 93; Jehangir 2010, 534).

Moreover, first-gen students often face difficulties in negotiating access to higher education and navigating the academy all while usually working longer hours that often lead to lower grades and higher attrition rates (Bell and Santamaría 2019a, 7). Many of these concerns have more to do with structural issues than with first-gen political science graduate students themselves. What is further important to note is that first-gen graduate students have shared narratives of great resilience to persevere through college and in graduate school (Gardner and Holley 2011, 82). In short, first-gen identity is not a deficiency. Indeed, first-gen political science graduate students have the capacity to tell their stories, change the narrative, and hence create better conditions themselves, for their families, and for their communities (Bell and Santamaría 2019a, 7).

As such, learning how to navigate the various levels of higher education is imperative for most first-gen students. Specifically, first-gen political science students must try to make sense of curricular and pedagogical processes that are specific to political science as a discipline - processes which are both uplifting and daunting, otherwise they may be rendered invisible (Jehangir 2010, 536). Further, political 
science graduate programs are multifaceted, and the nuances and complexities of graduate school can make navigating the 'system' seem impossible, but it is not.

\section{Why does it matter that you're a first-gen political science graduate student?}

If we seek higher graduation rates and greater success of political science graduates in the classroom, we need understand why it matters that someone is first-gen. First, it matters that first-gen identity itself has only gained traction in the past decade. As such, first-gen students have quickly shifted from a deficit archetype (a perspective that suggests minority groups come into college with deficiencies compared to the dominant or majority group, in this case continuing-generation students) to an assetsbased standard, which focuses on strengths (Ives and Castillo-Montoya 2020). In other words, first-gen students are resilient and are indeed worthy of entering and completing political science graduate programs. Second, it matters that first-gen political science graduate students are resilient because of the current realities most graduate students (both first- and continuing-gen) are currently facing, which will be discussed further below. Third, graduate first-gen issues matter because there remains the question of defining first-gen graduate students, especially as fewer folks have attended graduate school compared to completing an undergraduate degree (Van Galen and Sablan 2021, 1-2). For example, does a continuinggen student become a first-gen graduate student if a parent did not receive a master's degree?

What we do know is that graduate students do not always receive the same type of support or have the same types of resources dedicated to their personal and academic growth as undergraduates at the university-level. Instead, most graduate programing is handled on the departmental-level or by a Graduate College, and the programing generally does not focus on status or positionality as a first-gen student. In graduate school, first-gen students can perceive that their peers already know the fundamentals of what is expected, whereas they can feel like imposters about how to navigate the system, which means they can end up studying "twice as hard to learn how to maneuver in and out of the system, how to work the system, [and] how to learn" (Gardner and Holley 2011, 84). Indeed, structural issues impact first-gen students.

Consequently, first-gen graduate students can be left to navigate a system they know little about, and this is compounded by feeling torn between two communities (home/community and graduate school), lack of financial resources to apply to graduate programs or take the GRE (if required), and generally transitioning into a graduate program in political science. Additional challenges include navigating convoluted structures of university, such as financial aid and housing (with little to no monetary help from families), all while maintaining home responsibilities. Despite the fact, first-gen students regularly consider the desires of their families rather than their own personal goals. As such, family wishes manifest themselves in the course and programs they take, like political science (Jehangir 2010, 536). Simultaneously, families may fear the idea of "a new intellectualism" that pushes first-gen students to the margins at home and at university (Jehangir 2010, 537). This can critically impact how first-gen students feel. For instance, returning home after your first semester can be difficult when no one can understand what pressures you face or the new ideas you share. You may receive condescending comments, an inability to understand the questions you pose, or a failure to acknowledge the milestones you have reached. This can make you feel like you do not share the same values or beliefs as your family. If you are a prospective student, knowing you are first-gen can help prepare you for this. As an existing 
graduate student, take solace that you are not alone in these experiences and seek out shared first-gen spaces for a sense of community.

Furthermore, there exists a perception that a college degree is necessary for upward mobility (Azmitia et al. 2018, 90; Jehangir 2010, 534). While pursuit of a political science graduate degree may not necessarily be for post-PhD employment prospects, graduates do earn more than their undergraduate peers. This is important because 30-50\% of U.S. first-gen students drop out after their first year because they often feel unwelcome or like they do not fit in with the campus "ethos," experiencing heightened isolation (Azmitia et al. 2018, 92; Jehangir 2010, 534). The primary issue is that first-gen graduate students are more likely to be enrolled in graduate programs as part-time students than continuinggeneration students, who are more likely to be full-time. They are also more likely to delay entry into graduate programs (Seay et al. 2008, 17-19). Ultimately, if first-gen students do enroll in postsecondary education, they are less likely to graduate from college (Graf 2019,4). In light of all of this, there can be adverse mental health impacts which subsequently impact capacity to learn (Bell and Santamaría 2019b, 195).

\section{Advice on how you can excel as a first-gen political science graduate student}

Our first piece of advice for prospective political science graduate students - especially first-gen students from low-income backgrounds - is that you should compare programs that offer fellowships and assistantships as these forms of financial support are often vital for success in graduate school (Gardner and Holley 2011, 86). You should also identify a faculty member who could be a potential adviser as they can play a critical role in helping you frame your research interests, strategize in letters of recommendation, and prepare you with mock interviews as part of the application process to study political science at the graduate level (Wagner, Alderson, and Spetz 2020, 346). Additionally, pay attention to the value of the education on offer and the prestige among U.S. universities and how these will affect your post-PhD employment opportunities (Gardner and Holley 2011, 84).

For first-gen political science graduate students who have been accepted, you ought to consider preparing for your program. This will likely include ensuring that you are developing strong writing and communication skills, as well as some familiarity with data computation software such as Stata, R, SPSS, and Python. This also means having some familiarity with information acquisition, such as primary and secondary research methods, and qualitative and quantitative data collection and analytical methods (Seay et al. 2008, 20). In addition, you could begin reading foundational texts for classes that you will be enrolled in and this will ensure that the transition into political science graduate education is not as steep as it otherwise would be. You can identify these texts by reaching out to the Graduate Director of your department or faculty who will be teaching those classes. Most importantly, recognize the value that you bring to the discipline of political science. There may be times that you feel deflated, but you are worthy and able to embark on a graduate degree in political science just as much as continuing-generation students in your program (Gardner and Holley 2011, 83).

For current political science graduate students, you could participate in collaborative research opportunities with faculty members and these opportunities do not only assist in enhancing your employability and your research skills, but they also help to generate a sense of belonging, thereby offsetting the imposter syndrome that typically affects first-gen graduate students (Bell and Santamaría 
2019b, 205). You should be proud that you 'made it' this far, despite major obstacles to being a first-gen student in applying to and attending graduate school to study political science. Moreover, if you are struggling in your program, you can seek out support from your university - support in writing, presenting, reading, citing research (e.g., Zotero), and publishing and broadcasting research (e.g., Google Scholar, ResearchGate, LinkedIn) - which can often be found in campus writing and learning centers, library services, and departmental professionalization seminars. There are also social media communities for first-gen students on platforms like Twitter and Facebook, but be wary - while these platforms can be fruitful sources of information and create a virtual sense of belonging, they can also be a source of toxicity that can adversely affect your mental health. Given this, try to use social media in a balance that works best for you.

At some universities, short, one-credit classes are available for graduate students to boost their skills in these areas of professionalism, and these can be beneficial. Also, as a current student, you should not be afraid to seek support from your faculty adviser. If your adviser is not supportive, you should engage your department's Graduate Director, administrative staff, or Chair in seeking a faculty adviser who is more supportive and, ideally, understands the barriers you face as a first-gen graduate student. For first-gen students, you may also find targeted financial support at conferences when it comes to presenting academic research. For example, the American Political Science Association (APSA) offers, every year, an Accessibility Grant to assist students in attending APSA for the first time. Some other political science conferences sometimes do the same - keep an eye out for grants in conferences that often take place in a cyclical fashion, in Spring and Fall.

To cultivate a sense of belongingness, you can volunteer in on-campus organizations that engage in campus politics or assist younger graduate students, undergraduate students or even high school students (Azmitia et al. 2018, 94). This can also serve to retain first-gen students as you can provide mentorship and demonstrate that first-gen political science students can be successful and can attend graduate school. One example of engagement includes monthly coffee hours or forums with like-minded students and administrators to socialize and identify opportunities for improvement. Such opportunities may include requesting: on-campus financial resources for first-gen students to be clearer; appropriate guidance in navigating financial and well-being support; access to free or discounted printing credits, food, textbooks, prescription drugs, and health insurance; flexibility in extensions for academic papers and exams; opportunities for first-gen students to share their experiences in classrooms; and greater opportunities for interaction and collaboration with faculty. Further, we also recommend that you talk to your peers in your graduate program - whether they are first-gen or not - as this can help to address feelings of inadequacy, navigate cultural norms in the discipline of political science, and promote persistence and determination in achieving success in the discipline (Bell and Santamaría 2019a, 7; Seay et al. 2008, 20).

Finally, we acknowledge that first-gen students may also have multiple and often intersecting identities, such as being first-gen and LGBTQIA+, part of a religious minority, an international student, or part of a racial and ethnic minority, among other things. Thus, first-gen students and universities must both understand that challenges facing first-gen students cannot be isolated as they can be compounded by other issues, such as racism, and homophobia. As such, the first-gen identity becomes linked to other identities that can be equally or more important. Greater focus on navigating these other identities can be found in other chapters of this edited volume. And to conclude this chapter, we want to reiterate that you 
are worthy, as a first-gen student, of pursuing and completing a political science graduate degree. Further, we amplify the call for an asset-based approach that draws attention to the strengths and resiliency of first-gen students and the contributions they can make to the discipline of political science.

\section{References}

Azmitia, Margarita, Grace Sumabat-Estrada, Yeram Cheong, and Rebecca Covarrubias. 2018. "“Dropping Out Is Not An Option': How Educationally Resilient First-Generation Students See the Future.” New Directions for Child and Adolescent Development 160: 89-100. doi: 10.1002/cad.20240.

Bell, Amani, and Lorri J. Santamaría. 2019a. "Introduction: Why Focus on First Generation Students?" In Understanding Experiences of First Generation University Students: Culturally Responsive and Sustaining Methodologies, eds. Amani Bell and Lorri J. Santamaría, 1-25. New York: Bloomsbury Publishing.

Bell, Amani, and Lorri J. Santamaría. 2019b. "Conclusion: Beyond Listening to First Generation Students." In Understanding Experiences of First Generation University Students: Culturally Responsive and Sustaining Methodologies, eds. Amani Bell and Lorri J. Santamaría, 191-218. New York: Bloomsbury Publishing.

Gardner, Susan K., and Karri A. Holley. 2011. “"Those invisible barriers are real': The Progression of First-Generation Students Through Doctoral Education.” Equity \& Excellence in Education 44(1): 77-92. doi: 10.1080/10665684.2011.529791.

Graf, Anne Jumonville. 2019. "First-Generation Students and Libraries: Beyond the Deficit Narrative.” In Supporting Today's Students in the Library: Strategies for Retaining and Graduating International, Transfer, First-Generation, and Re-Entry Students, eds. Ngoc-Yen Tran and Silke Higgins. Chicago, IL: Association of College and Research Libraries, 3-21.

Ives, Jillian, and Milagros Castillo-Montoya. 2020. "First-Generation College Students as Academic Learners: A Systematic Review. Review of Educational Research 90(2): 139-178. doi: 10.3102/0034654319899707.

Jehangir, Rashné. 2010. "Stories as Knowledge: Bringing the Lived Experience of First-Generation College Students Into the Academy." Urban Education 45(4): 533-553. doi: 10.1177/0042085910372352.

NASPA. 2017. "Defining First-Generation.” Center for First-Generation Student Success [website], October 20, 2021. https://firstgen.naspa.org/blog/defining-first-generation.

Seay, Sandra E., Donald E. Lifton, Karl L. Wuensch, Lynn K. Bradshaw, and James O. McDowelle. 2008. "First-Generation Graduate Students and Attrition Risks." The Journal of Continuing Higher Education 56(3): 11-25. doi: 10.1080/07377366.2008.10400158.

Van Galen, Jane A., and Jaye Sablan. 2021. "Introduction: First-Generation PhDs Navigating Institutional Power in Early Academic Careers.” In Amplified Voices, Intersecting Identities, Volume 2: First- 
Thomas S. Benson and T. Mark Montoya

Generation PhDs Navigating Institutional Power in Early Academic Careers, eds. Jane A. Van Galen and Jaye Sablan, 1-17. Leiden, Netherlands: Brill Sense.

Wagner, Laura M., Alece Alderson, and Joanne Spetz. 2020. "Admission of First Generation to College Pre-licensure Master's Entry and Graduate Nursing Students.” Journal of Professional Nursing 36(5): 343-347. doi: 10.1016/j.profnurs.2020.02.001. 